Research Paper

\title{
Gender disparity in the survival of patients with primary myelodysplastic syndrome
}

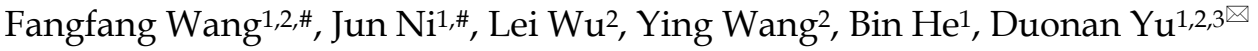 \\ 1. Clinical Medical College, Yangzhou University, Yangzhou 225001, China \\ 2. Jiangsu Key Laboratory of Experimental \& Translational Non-coding RNA Research, Yangzhou University School of Medicine, Yangzhou 225001, China \\ 3. Jiangsu Co-Innovation Center for Prevention and Control of Important Animal Infectious Disease and Zoonosis, Yangzhou 225001, China \\ \# These authors contributed equally to this work \\ $\bowtie$ Corresponding author: Duonan Yu, Clinical Medical College, Yangzhou University, Yangzhou 225001, China. Email: dnyu@yzu.edu.cn
}

(1) Ivyspring International Publisher. This is an open access article distributed under the terms of the Creative Commons Attribution (CC BY-NC) license (https://creativecommons.org/licenses/by-nc/4.0/). See http://ivyspring.com/terms for full terms and conditions.

Received: 2018.06.30; Accepted: 2018.12.17; Published: 2019.01.30

\begin{abstract}
Several prognostic scoring systems have been developed to assess prognosis in myelodysplastic syndrome (MDS). However, currently there are no systems that list gender as a prognostic factor. We queried a National Cancer Institute database to investigate the prognostic influence of gender on the survival of patients with MDS. We first identified 34,681 qualified patients diagnosed with MDS from 2001-2014 in the Surveillance, Epidemiology, and End Results (SEER) database, and then analyzed the characteristics of these patients using chi-squared tests. The Kaplan-Meier method and the multivariate Cox regression model were used to examine whether gender disparity in the survival of patients with MDS existed. We found that male patients had higher incidence rate of MDS $(55.3 \%$ vs $44.7 \%, \mathrm{P}<0.001)$ and a significant survival disadvantage $(27.6 \%$ vs $33.6 \%, \mathrm{P}<0.001)$ compared to female patients. Moreover, the less favorable survival rate of male MDS patients was associated with the age at diagnosis, race, marital status at diagnosis and the histological subtypes including refractory anemia (RA), refractory cytopenia with multilineage dysplasia (RCMD), myelodysplastic associated with isolated del 5q (MDS 5q-), myelodysplastic/myeloproliferative neoplasm (MDS/MPN) and not otherwise specified (NOS). In conclusion, gender can be considered as an independent prognostic factor for the overall survival of patients with MDS.
\end{abstract}

\section{Introduction}

Myelodysplastic syndrome (MDS) comprises a heterogeneous group of clonal myeloid disorders characterized by debilitating peripheral blood cytopenias, abnormal blood cell development, and clonal genetic markers ${ }^{1}$. MDS is typically considered as a neoplasm because of frequent genetic aberrations, limited patient survival, and progression to acute myeloid leukemia (AML) ${ }^{2}$. Moreover, MDS is a collection of disorders with a wide range of outcomes. Some patients have a near-normal life expectancy without severe clinical symptoms and signs, while others die of complications associated with bone marrow failure, including infection, hemorrhage, and iron overload. Therefore, accurate risk assessment and prediction of prognosis are of great importance to the optimal clinical management for individual MDS cases.

Several prognostic systems, including the International Prognostic Scoring System (IPSS), the revised International Prognostic Scoring System (IPSS-R), and the World Health Organization (WHO)-based Prognostic Scoring System (WPSS) have been developed to predict the prognosis of MDS 3-7. Reference prognostic variables include but are not limited to marrow blasts, cytogenic and molecular abnormalities, hemoglobin level, platelet numbers, absolute neutrophil count and transfusion dependence $3,4,6,8,9$. The MDS comorbidity index (MDS-CI), consisting of cardiac, liver, renal, 
pulmonary diseases and solid tumors, is also evaluated as a prognostic factor ${ }^{10}$. Additional factors such as serum albumin level ${ }^{11}$, serum ferritin level ${ }^{12}$, presence of bone marrow fibrosis 13, degree of eosinophilia and basophilia ${ }^{14}$, and $\beta 2$ microglobulin level ${ }^{15-16}$ were of prognostic values. Moreover, certain features such as age, race-ethnicity and marital status at diagnosis, which are not directly associated with disease, are valuable for predicting prognosis of MDS patients ${ }^{8}$.

In contrast, little is known about the relationship between gender and the outcomes of patients with MDS. In the original IPSS, gender was stated to have predictive importance for survival in MDS patients but was not quantified as a prognostic factor in the scoring system ${ }^{3}$. Although a study analyzing 897 MDS patients further demonstrated gender as a potential prognostic factor 17 , gender was still not recognized as a variable in multiple prognostic systems, including the recent WHO classification system updated in $2016{ }^{18}$. In this study, we evaluated the prognostic value of gender in a large cohort of patients with MDS from the Surveillance, Epidemiology and End Results (SEER) database and explored the association of gender disparity with various factors including age at diagnosis, marital status at diagnosis and histological types. The analysis of 34,681 MDS cases indicates that gender has a strong association with the prognosis of MDS patients.

\section{Materials and Methods}

\subsection{Data source}

Data presented in this paper were obtained using the SEER Program, sponsored by the National Cancer Institute. The current SEER database comprises 18 population-based cancer registries acquired from 1973 to 2014, which represent approximately $28 \%$ of the population in the United States of America 19-20. The SEER registries collect data such as patients' demographics, stage at diagnosis, age of diagnosis, cancer characteristics, follow-up information, survival months, and vital status.

\subsection{Study Population}

We limited the histological types of MDS using ICD-O-3 morphology codes (9975, 9980-9992) (Table 1). Exclusion criteria were as follows: (1) patients with more than one malignancies, but MDS was secondary $(\mathrm{n}=14668) ; \quad(2)$ patients diagnosed without microscopic confirmation or diagnostic confirmation ${ }^{21}(\mathrm{n}=3177)$; (3) patients diagnosed through autopsy or determined by death certificate $(n=13) ;(4)$ patients with unknown race ( $\mathrm{n}=592)$; (6) patients with unknown marital status at diagnosis $(n=3496)$. Cases were acquired after 2001 because only a few patients were included in the SEER database before 2001 (total seven patients in 1986-2000). In all, our analysis included 34,681 primary MDS patients who were followed from the date of diagnosis till death or to the end of follow-up (December 31, 2014).

\subsection{Statistical analysis}

The covariates of interest included gender (male and female), age in years $(<60,60-69,70-79$, and $\geq 80)$, race (white, black, and other), year of diagnosis (2001-2007 and 2008-2014), marital status at diagnosis (married, never married, divorced/separated and widowed) and histological types (RA, RN, RT, RARS, RCMD, RAEB, RAEB-t, MDS 5q-, MDS/MPN, t-MDS, and MDS-NOS) ${ }^{21}$ (Table 1).

The chi-squared test was performed to evaluate the significance of differences in the frequencies of patients' baseline characteristics between males and females. Five-year survival associated with covariates was estimated using the Kaplan-Meier method. The log-rank test was used to determine the statistical significance of the differences in survival distributions for each covariate. We used univariate and multivariate Cox regression models to assess the differences in survival according to gender, age, race, year of diagnosis, marital status, and various histological types. The statistical analyses were performed using the statistical software package SPSS for Windows, version 22 (IBM Corp, Armonk, NJ, USA). $\mathrm{P}<0.05$ (two-sided) defined statistical significance.

\section{Results}

\subsection{Incidence of MDS}

We counted all types of MDS (Table 1) and found a marked increase of registered annual cases of MDS starting in 2001 (Figure 1). There were only seven MDS patients recorded in the database before 2001, and 1,856 patients (male, 1006; female, 850) recorded in 2001 alone. Overall, annual cases of MDS in both males and females gradually increased between 2002 to 2014, and the proportion of MDS among males was higher compared with that of females $(55.3 \%$ vs $44.7 \%, \mathrm{P}<0.001)$ (Table 2$)$.

\subsection{Baseline characteristics of patients}

Using the chi-squared test, we examined baseline characteristics of MDS patients. Patient demographics and pathological features are summarized in Table 2. We identified 34,681 patients with MDS from 2001 to 2014, including 19,193 males and 15,488 females. We observed differences in the distributions of male and female MDS patients associated with age, race-ethnicity, year of diagnosis, marital status, and histological types. Morbidity of 
male and female patients was associated with majority of these variables.

Table 1. Coding myelodysplastic syndrome using the International Classification of Diseases for Oncology, 3rd Edition (ICD-O-3).

\begin{tabular}{lll}
\hline MDS & Abbreviation & ICD-O-3 \\
\hline Refractory anemia & RA & 9980 \\
Refractory neutropenia & RN & 9991 \\
Refractory thrombocytopenia & RT & 9992 \\
Refractory anemia with ring sideroblasts & RARS & 9982 \\
Refractory cytopenia with multilineage dysplasia & RCMD & 9985 \\
Refractory anemia with excess blasts & RAEB & 9983 \\
Refractory anemia with excess blasts in transformation & RAEB-t & 9984 \\
Myelodysplastic associated with isolated del 5q & 5q- & 9986 \\
Myelodysplastic/Myeloproliferative neoplasm, & MDS/MPN & 9975 \\
unclassifiable & & \\
Therapy-related myelodysplastic syndrome & t-MDS & 9987 \\
Myelodysplastic syndrome, NOSs & MDS-NOS & 9989 \\
\hline
\end{tabular}

sNot otherwise specified.

Table 2. Baseline demographics and characteristics of patients with MDS included in the SEER database, 2001-2014.

\begin{tabular}{|c|c|c|c|c|}
\hline \multirow[t]{2}{*}{ Characteristics } & Total & Male & Female & \multirow[t]{2}{*}{$\mathbf{P}$} \\
\hline & $(n=34681) N(\%)$ & $(n=19193)$ N (\%) & $(n=15488)$ N (\%) & \\
\hline Incidence rate $(\%)$ & & 55.3 & 44.7 & \\
\hline Median age & $76(66-83)$ & $75(66-82)$ & $77(67-84)$ & \\
\hline Age & & & & $<0.001$ \\
\hline$<60 y$ & 4832(13.9) & 2615(13.6) & $2217(14.3)$ & \\
\hline $60-69 y$ & 6291(18.1) & 3786(19.7) & $2505(16.2)$ & \\
\hline $70-79 y$ & 10944(31.6) & 6353(33.1) & 4591(29.6) & \\
\hline$\geq 80 \mathrm{y}$ & 12614(36.4) & $6439(33.5)$ & 6175(39.9) & \\
\hline Race & & & & $<0.001$ \\
\hline White & 29313(84.5) & 16514(86.0) & $12799(82.6)$ & \\
\hline Black & $2911(8.4)$ & 1312(6.8) & 1599(10.3) & \\
\hline Other§ & $2457(7.1)$ & 1367(7.1) & $1090(7.0)$ & \\
\hline Year of diagnosis & & & & 0.035 \\
\hline 2001-2007 & 15433(44.5) & $8444(44.0)$ & $6989(45.1)$ & \\
\hline 2008-2014 & 19248(55.5) & $10749(56.0)$ & 8499(54.9) & \\
\hline Marital status & & & & $<0.001$ \\
\hline Married & 19080(55.0) & 13134(68.4) & $5946(38.4)$ & \\
\hline Never married & 3934(11.3) & 2171(11.3) & 1763(11.4) & \\
\hline Divorced/Separated & $3021(8.7)$ & $1427(7.4)$ & 1594(10.3) & \\
\hline Widowed & $8646(24.9)$ & 2461(12.8) & 6185(39.9) & \\
\hline Histologic type & & & & $<0.001$ \\
\hline RA & $3495(10.1)$ & $1768(9.2)$ & 1727(11.2) & \\
\hline RN & $2(0)$ & $0(0)$ & $2(0)$ & \\
\hline
\end{tabular}

\begin{tabular}{|c|c|c|c|}
\hline Characteristics & Total & Male & Female \\
\hline & $(n=34681) N(\%)$ & $(n=19193) N(\%)$ & $(\mathrm{n}=15488) \mathrm{N}(\%)$ \\
\hline RT & $86(0.2)$ & $43(0.2)$ & $43(0.3)$ \\
\hline RAS & $2662(7.7)$ & $1455(7.6)$ & $1207(7.8)$ \\
\hline RCMD & $2016(5.8)$ & $1320(6.9)$ & $696(4.5)$ \\
\hline RAEB & $4717(13.6)$ & 2892(15.1) & 1825(11.8) \\
\hline RAEB-t & $153(0.4)$ & $90(0.5)$ & $63(0.4)$ \\
\hline MDS 5q- & $851(2.5)$ & $317(1.7)$ & $534(3.4)$ \\
\hline MDS/MPN & $1666(4.8)$ & $840(4.4)$ & $826(5.3)$ \\
\hline t-MDS & $129(0.4)$ & $67(0.3)$ & $62(0.4)$ \\
\hline MDS-NOS & $18904(54.5)$ & $104018(54.2)$ & $8503(54.9)$ \\
\hline
\end{tabular}

The median age of the qualified MDS patients at diagnosis was 76 years (interquartile range, 66-83 years). Female patients were not significantly older than male patients at the time of diagnosis (median 77 years vs 75 years, respectively). The numbers of male and female patients increased gradually with age. Patients aged $\geq 80$ years had the highest prevalence of MDS compared with those in the $<60$ years, 60-69 years and 70-79 years age groups. We also observed that white patients have the highest proportion of MDS and that most male patients were married. Further, in both male and female MDS patients, the most common histological type (accounting for more than 50\%) is MDS-NOS (not otherwise specified). The prevalence of refractory anemia (RA) and refractory anemia with excess blasts (RAEB) was also high in both genders.

\subsection{Survival analysis}

Univariate analysis revealed that male, age $\geq 80$ years, non-black, widowed, and histological types RAEB and refractory anemia with excess blasts in transformation (RAEB-t) were significant risk factors for poor survival, and multivariate analysis confirmed that gender, age, and marital status were independent prognostic factors (Table 3). Specifically, 5-year survival was $27.6 \%$ for all male patients (HR 1.243, 95\% CI 1.209-1.278, $\mathrm{P}<0.001$ ) and $33.6 \%$ for all female patients $(\mathrm{P}<0.001)$ (Table 3 and Figure 2). There was

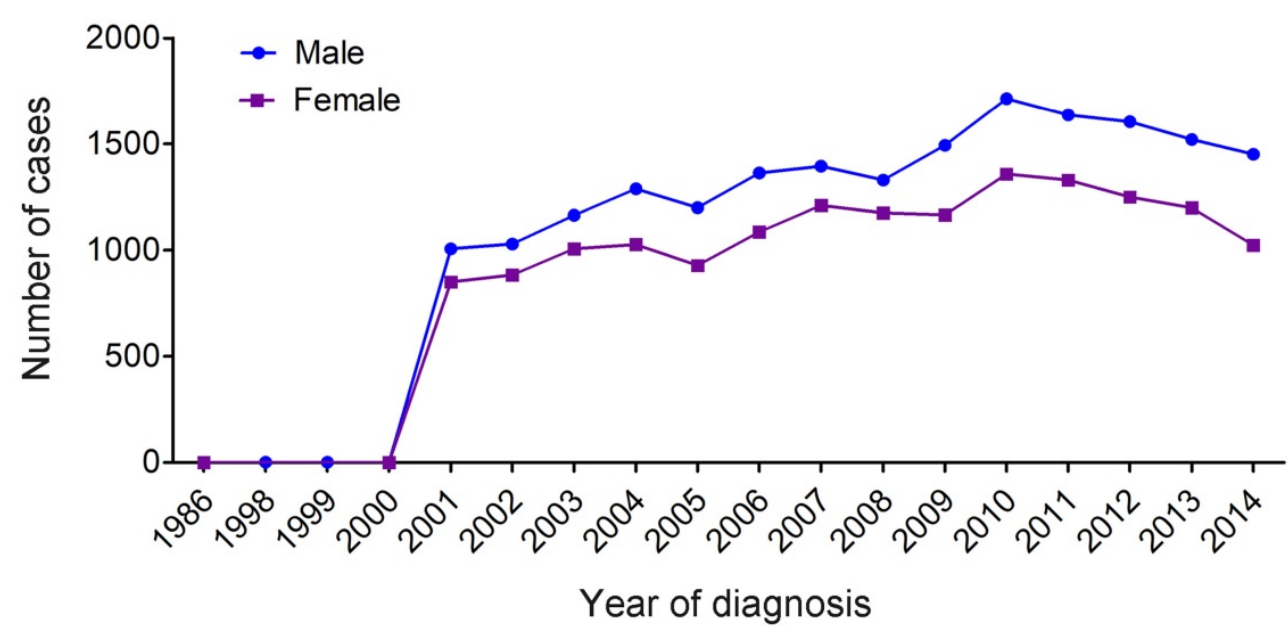

Figure 1. Temporal changes in the estimated annual cases of MDS over the time span covered in the study (period estimates for 1986-2014). 
also survival disadvantage for widowed male patients (HR 1.381, 95\%CI 1.341-1.423). Black patients experienced advantage of survival compared with white patients (HR 0.912, 95\% CI 0.868-0.958, $\mathrm{P}<0.001)$. RAEB and RAEB-t were histological subtypes with leading hazard risks of mortality. In contrast, RA, refractory anemia with ring sideroblasts (RARS), and myelodysplastic/myeloproliferative neoplasm, unclassifiable (MDS/MPN) were associated with favorable survival outcomes (Table 3).

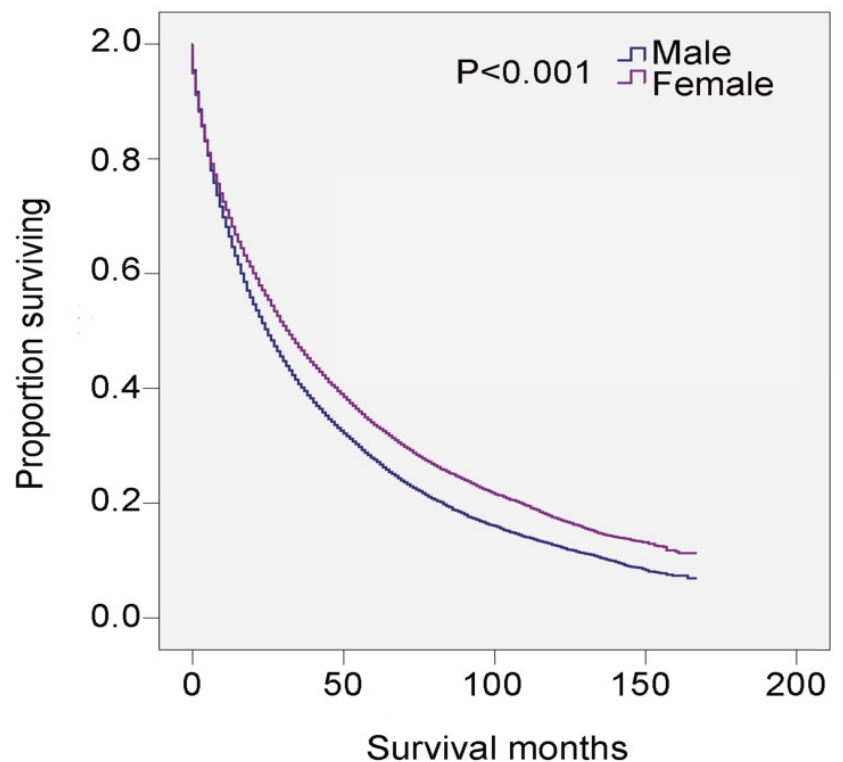

Figure 2. SEER data, 2001-2014. Changes in survival of male and female patients with MDS

Table 3. Univariate and multivariate regression analysis of the influence of factors on the survival of patients with MDS.

\begin{tabular}{|c|c|c|c|c|c|}
\hline \multirow[t]{2}{*}{ Variable } & \multirow{2}{*}{$\begin{array}{l}5 \text {-year } \\
\text { survival }\end{array}$} & \multicolumn{2}{|c|}{$\begin{array}{l}\text { Univariate } \\
\text { analysis }\end{array}$} & \multicolumn{2}{|c|}{ Multivariate analysis } \\
\hline & & $\begin{array}{l}\text { Log rank } \\
\chi^{2} \text { test }\end{array}$ & $\mathbf{P}$ & HR $(95 \% C I)$ & $\mathbf{P}$ \\
\hline Gender & & 153.143 & $<0.001$ & & \\
\hline Male & $27.6 \%$ & & & $1.243(1.209-1.278)$ & $<0.001$ \\
\hline Female & $33.6 \%$ & & & Reference & \\
\hline Age & & 2779.272 & $<0.001$ & & \\
\hline$<60 y$ & $52.7 \%$ & & & Reference & \\
\hline $60-69 y$ & $40.2 \%$ & & & $1.540(1.459-1.624)$ & $<0.001$ \\
\hline $70-79 y$ & $30.7 \%$ & & & $2.034(1.937-2.137)$ & $<0.001$ \\
\hline$\geq 80 y$ & $16.9 \%$ & & & $3.014(2.868-3.167)$ & $<0.001$ \\
\hline Race & & 101.353 & $<0.001$ & & \\
\hline White & $29.4 \%$ & & & Reference & \\
\hline Black & $38.7 \%$ & & & $0.912(0.868-0.958)$ & $<0.001$ \\
\hline Other $§$ & $31.6 \%$ & & & 0.993(0.944-1.046) & 0.801 \\
\hline Year of diagnosis & & 5.233 & 0.022 & & \\
\hline $2001-2007$ & $30.8 \%$ & & & Reference & \\
\hline 2008-2014 & $29.7 \%$ & & & $1.018(0.990-1.046)$ & 0.212 \\
\hline Marital Status & & 568.582 & $<0.001$ & & \\
\hline Married & $33.0 \%$ & & & Reference & \\
\hline \multirow[t]{2}{*}{ Never married } & $36.9 \%$ & & & $0.910(0.870-0.950)$ & $<0.001$ \\
\hline & $31.6 \%$ & & & $1.060(1.011-1.111)$ & 0.015 \\
\hline \multicolumn{6}{|c|}{ Divorced/Separated } \\
\hline Widowed & $21.4 \%$ & & & $1.381(1.341-1.423)$ & $<0.001$ \\
\hline Histologic Type & & 2113.316 & $<0.001$ & & \\
\hline RA & $40.7 \%$ & & & Reference & \\
\hline RN & - & & & - & \\
\hline
\end{tabular}

\begin{tabular}{|c|c|c|c|c|}
\hline \multirow[t]{2}{*}{ Variable } & \multirow[t]{2}{*}{$\begin{array}{l}5 \text {-year } \\
\text { survival }\end{array}$} & $\begin{array}{l}\text { Univariate } \\
\text { analysis }\end{array}$ & \multicolumn{2}{|c|}{ Multivariate analysis } \\
\hline & & $\begin{array}{ll}\text { Log rank } P \\
X^{2} \text { test }\end{array}$ & HR $(95 \% \mathrm{CI})$ & $\mathbf{P}$ \\
\hline RT & - & & - & \\
\hline RAS & $46.4 \%$ & & $0.851(0.799-0.906)$ & $<0.001$ \\
\hline RCMD & $28.0 \%$ & & $1.365(1.275-1.461)$ & $<0.001$ \\
\hline RAEB & $11.2 \%$ & & $2.686(2.549-2.831)$ & $<0.001$ \\
\hline RAEB-t & $8.5 \%$ & & $3.240(2.739-3.834)$ & $<0.001$ \\
\hline MDS 5q- & $28.5 \%$ & & $1.326(1.210-1.453)$ & $<0.001$ \\
\hline MDS/MPN & $46.2 \%$ & & $1.014(0.924-1.112)$ & 0.770 \\
\hline t-MDS & $26.6 \%$ & & $1.703(1.406-2.062)$ & $<0.001$ \\
\hline MDS-NOS & $30.2 \%$ & & $1.302(1.245-1.361)$ & $<0.001$ \\
\hline
\end{tabular}

Table 4. Univariate analysis of the influence of factors on the 5 -years survival of the patients with MDS.

\begin{tabular}{|c|c|c|c|}
\hline Variable & Male & Female & $\mathbf{P}$ \\
\hline \multicolumn{4}{|l|}{ Age } \\
\hline$<60 \mathrm{y}$ & $47.1 \%$ & $59.3 \%$ & $<0.001$ \\
\hline $60-69 y$ & $36.0 \%$ & $46.4 \%$ & $<0.001$ \\
\hline $70-79 y$ & $27.5 \%$ & $35.1 \%$ & $<0.001$ \\
\hline$\geq 80 \mathrm{y}$ & $15.2 \%$ & $18.7 \%$ & $<0.001$ \\
\hline \multicolumn{4}{|l|}{ Race } \\
\hline White & $26.9 \%$ & $32.7 \%$ & $<0.001$ \\
\hline Black & $34.7 \%$ & $41.8 \%$ & $<0.001$ \\
\hline Other $^{\S}$ & $26.7 \%$ & $28.3 \%$ & 0.045 \\
\hline \multicolumn{4}{|l|}{ Year of diagnosis } \\
\hline $2001-2007$ & $28.1 \%$ & $34.5 \%$ & $<0.001$ \\
\hline 2008-2014 & $27.2 \%$ & $32.7 \%$ & $<0.001$ \\
\hline \multicolumn{4}{|l|}{ Marital Status } \\
\hline Married & $29.1 \%$ & $41.5 \%$ & $<0.001$ \\
\hline Never married & $32.4 \%$ & $42.4 \%$ & $<0.001$ \\
\hline Divorced/Separated & $27.3 \%$ & $35.4 \%$ & $<0.001$ \\
\hline Widowed & $16.1 \%$ & $23.6 \%$ & $<0.001$ \\
\hline \multicolumn{4}{|l|}{ Histologic Type } \\
\hline RA & $35.0 \%$ & $46.5 \%$ & $<0.001$ \\
\hline RN & - & - & - \\
\hline RT & - & - & - \\
\hline RAS & $47.1 \%$ & $45.4 \%$ & 0.683 \\
\hline RCMD & $26.0 \%$ & $31.7 \%$ & 0.035 \\
\hline RAEB & $10.6 \%$ & $12.3 \%$ & 0.334 \\
\hline RAEB-t & $10.0 \%$ & $6.3 \%$ & 0.532 \\
\hline MDS 5q- & $22.1 \%$ & $32.3 \%$ & $<0.001$ \\
\hline MDS/MPN & $44.4 \%$ & $47.9 \%$ & 0.015 \\
\hline $\mathrm{t}$-MDS & $26.8 \%$ & $26.3 \%$ & 0.546 \\
\hline MDS-NOS & $27.7 \%$ & $33.2 \%$ & $<0.001$ \\
\hline
\end{tabular}

$\begin{array}{llll}\text { MDS-NOS } & 27.7 \% & 33.2 \% & <0.001\end{array}$

sOther includes American Indians/Alaska natives, Asian/Pacific Islanders. Unable to statistics the 5-year survival of RN and RT because no data in the SEER.

Next, we analyzed whether the effects of gender on survival was related to other independent prognostic factors. Male MDS patients in each of the four age subgroups had shorter survival than that of females in the same age subgroups (Figure 3A-3D, Table 4). To examine the survival distributions between each gender as functions of race-ethnicity, we found that all male patients, regardless of white, black or other races, had a higher probability of mortality compared with that of females in the same race-ethnicity groups (Figure 3I-3K, Table 4). We also found that the mortality of both married and unmarried (including never married, divorced/ separated and widowed) males exceeded that of married and unmarried females, respectively. Especially, males in the widowed group have the 
highest mortality (Figure 3E-3H, Table 4). Additionally, the survival of male patients was significantly shorter among those with histological subtypes RA, refractory cytopenia with multilineage dysplasia (RCMD), MDS associated with isolated del 5q (MDS 5q-), MDS/MPN and MDS-NOS (Figure 4 and Table 4). However, no significant survival difference could be detected between genders in patients with RARS, RAEB, RAEB-t, and therapy-related MDS (t-MDS) (Figure 4 and Table 4). All data indicated that gender as a single factor had a significant impact on the survival of patients diagnosed with MDS.

\section{Discussion}

MDS was considered as a preleukemic condition and was eventually confirmed as a myeloid neoplasm 2 22. In 2000 , the WHO changed the behavior code for MDS in the International Classification of Diseases for Oncology (ICD-O) from 1 (uncertain whether benign or malignant) to 3 (malignant) ${ }^{23-25}$. Subsequently,
MDS became reportable to population-based cancer registries. Furthermore, with greater awareness of the classification of MDS published by the WHO in 2001, which incorporated not only morphologic information but also biologic and genetic information 26 and better diagnostic techniques, the number of registered patients with MDS significantly increased in 2001 and thereafter. Moreover, general annual cases of MDS increased dramatically with advancing ages. Among them, men were shown to have higher annual cases of MDS compared with women.

We found not only a significant effect of gender on the incident rate of MDS patients but also variation of survival between genders among subgroups by age at diagnosis, race, marital status at diagnosis and MDS subtypes. Male patients had significantly shorter survival compared with that of females, which has been validated by Asian and European MDS cohorts (supplementary table 1) ${ }^{27-31}$. The higher mortality rates of male patients with MDS might be explained by the increased presence of comorbidities upon

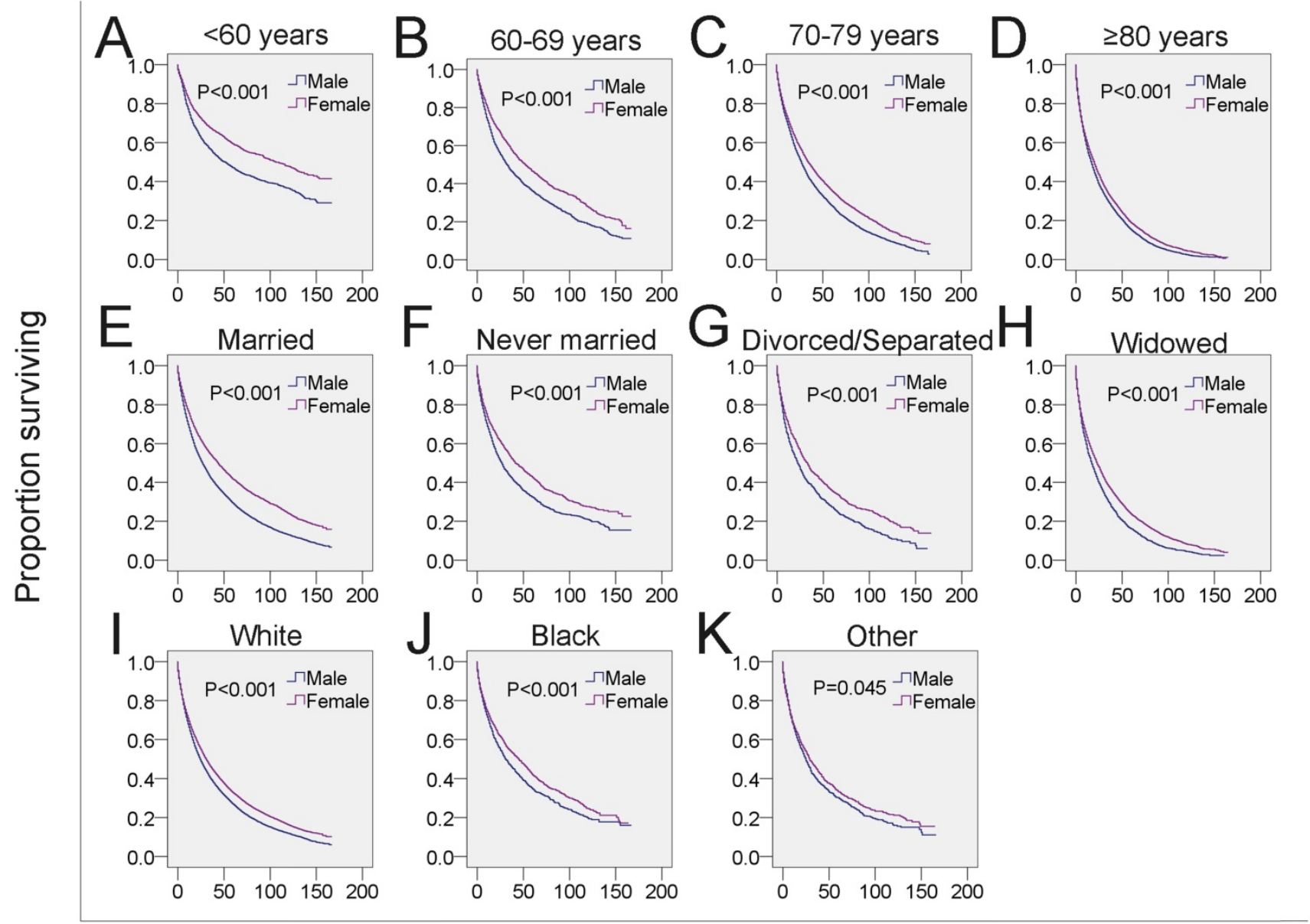

\section{Survival months}

Figure 3. SEER survival data (2001-2014). Changes in survival of male and female patients with MDS for each specific age, marital and race group. A-D: Survival of male and female patients with MDS across subgroups of age at diagnosis. E-H: Survival of male and female patients with MDS across subgroups of marital status. I-K: Survival of male and female patients with MDS across subgroups of race-ethnicity. 


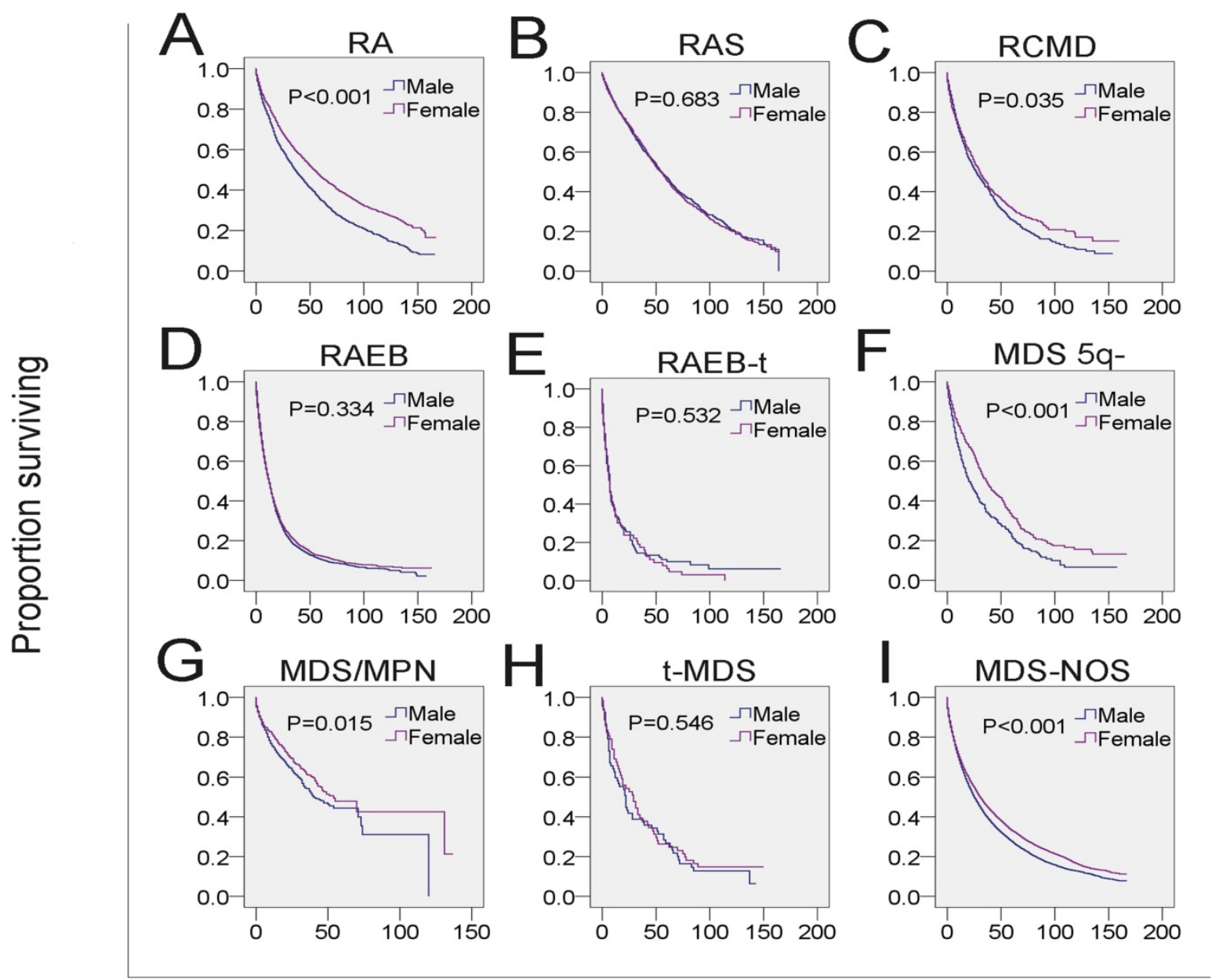

\section{Survival months}

Figure 4. SEER survival data (2001-2014). Change in survival of male and female patients with MDS for each histological type.

diagnosis ${ }^{32-33}$. A higher frequency of cardiovascular diseases, severe pulmonary and liver diseases was more often observed in male than female patients 32,34 , while large cohort-based studies confirmed that MDS patients with the above comorbidities had significantly greater risk of death than those without comorbidities 24, 35. The presence of comorbidities might influence therapeutic decision-making, often limiting preferred choices and aggressiveness of treatment options. For instance, we usually do not treat MDS-RAEB patients who have congestive heart failure (CHF) with chemotherapeutic drug anthracyclines due to its cardiac toxicity. However, therapeutics with less adverse effects on cardiac function was proved to not be the best choice since factors such as anemia from MDS and its related iron overload could further aggravate heart failure.

In addition to the factors described above, other possible explanations of the shorter survival of male MDS patients might include the association with molecular abnormities such as faster methylome aging and shorter telomeres ${ }^{36-37}$, both of which often correlate with shorter survival $37-39$. Less benefit from treatment might be another reason for short survival of male patients. Male MDS patients expressed higher level of cytidine deaminase (CDA) than that of females ${ }^{40}$, whereas $C D A$ could rapidly inactivate the activities of decitabine (DAC) and azacitidine (AZA), two 5-methylated cytidine analogs commonly used for the treatment of MDS patients 40-41. These male-specific responses might affect the outcome of DAC or AZA therapeutics and cause increased mortality.

We also found that the increased risk of mortality of male patients was associated with RA, RCMD, MDS 5q-, MDS/MPN and MDS-NOS, but not other subtypes, indicating that survival varied as a function of gender across the MDS histological subtypes. Since the SEER database lacked information for molecular biomarker, comorbidities, gene mutation and therapeutic data, we could not determine in this study whether these parameters were correlated to the histological subtypes which were associated with poor prognosis. These 
parameters could affect the path of disease progression or therapeutic strategies, and thus might have significant impact on the survival of patients with MDS. For example, molecular biomarkers or genetic information may help monitor disease progression or relapse and predict the response to specific therapies. This notion is supported by the finding that some male MDS patients with cytogenetic abnormalities $-7 / \operatorname{del}(7 q)$ or $\operatorname{inv}(3) / t(3 q) / \operatorname{del}(3 q)$ represent poor prognosis because they cannot receive aggressive treatment due to the presence of severe comorbidities ${ }^{4}$.

In general, this study on the overall survival of MDS patients is based on the largest cohort and authoritative datasets of MDS patients. The poorer prognosis of male patients strongly suggests that gender can be used as an independent prognostic predictor for overall survival in patients with MDS.

\section{Supplementary Material}

Supplementary table.

http://www.jcancer.org/v10p1325s1.pdf

\section{Acknowledgments}

This study used data from the SEER database and we are grateful for the efforts of the SEER tumor registries program. Interpretation and reporting of these data are the sole responsibility of the authors. This work is supported by the National Natural Science Foundation of China (Grant No. 81670186 and 81470277, DY), the Priority Academic Program Development of Jiangsu Higher Education Institution (Veterinary Medicine, DY), and the Natural Science Foundation of Jiangsu Province of China (15KJA320007, DY).

\section{Author Contributions}

D.Y., F.W. and J.N. designed the study. F.W., J.N., L.W., Y.W. and B.H. analyzed the data. F.W. and J.N. drafted the manuscript. D.Y. revised the manuscript.

\section{Competing Interests}

The authors have declared that no competing interest exists.

\section{References}

1. Dao KT. Myelodysplastic Syndromes: Updates and Nuances. Med Clin North Am. 2017; 101(2): 333-50.

2. Natelson EA, Pyatt D. Acquired myelodysplasia or myelodysplastic syndrome: clearing the fog. Adv Hematol. 2013; 2013: 309637.

3. Greenberg P, Cox C, LeBeau MM, et al. International scoring system for evaluating prognosis in myelodysplastic syndromes. Blood. 1997; 89(6): 2079-88.

4. Greenberg PL, Tuechler H, Schanz J, et al. Revised international prognostic scoring system for myelodysplastic syndromes. Blood. 2012; 120(12): 2454-65.

5. Della Porta MG, Tuechler H, Malcovati L, et al. Validation of WHO classification-based Prognostic Scoring System (WPSS) for myelodysplastic syndromes and comparison with the revised International Prognostic Scoring System (IPSS-R). A study of the International Working Group for Prognosis in Myelodysplasia (IWG-PM). Leukemia. 2015; 29(7): 1502-13.
6. Malcovati L, Della Porta MG, Strupp C, et al. Impact of the degree of anemia on the outcome of patients with myelodysplastic syndrome and its integration into the WHO classification-based Prognostic Scoring System (WPSS). Haematologica. 2011; 96(10): 1433-40.

7. Komrokji RS, Corrales-Yepez M, Al Ali N, et al. Validation of the MD Anderson Prognostic Risk Model for patients with myelodysplastic syndrome. Cancer. 2012; 118(10): 2659-64.

8. Bejar R. Clinical and genetic predictors of prognosis in myelodysplastic syndromes. Haematologica. 2014; 99(6): 956-64.

9. Duong $\mathrm{VH}$, Padron $\mathrm{E}, \mathrm{Al}$ Ali $\mathrm{NH}$, et al. The prognostic value of circulating myeloblasts in patients with myelodysplastic syndromes. Ann Hematol. 2018; 97(2): 247-54.

10. Jonas BA, Greenberg PL. MDS prognostic scoring systems-Past, present, and future. Best Pract Res Clin Haematol. 2015; 28(1): 3-13.

11. Komrokji RS, Corrales-Yepez M, Kharfan-Dabaja MA, et al. Hypoalbuminemia is an independent prognostic factor for overall survival in myelodysplastic syndromes. Am J Hematol. 2012; 87(11): 1006-9.

12. Malcovati L, Porta MG, Pascutto C, et al. Prognostic factors and life expectancy in myelodysplastic syndromes classified according to WHO criteria: a basis for clinical decision making. J Clin Oncol. 2005; 23(30): 7594-603.

13. Della Porta MG, Malcovati L, Boveri E, et al. Clinical relevance of bone marrow fibrosis and CD34-positive cell clusters in primary myelodysplastic syndromes. J Clin Oncol. 2008; 27(5): 754-62.

14. Wimazal F, Germing U, Kundi M, et al. Evaluation of the prognostic significance of eosinophilia and basophilia in a larger cohort of patients with myelodysplastic syndromes. Cancer. 2010; 116(10): 2372-81.

15. Gatto S, Ball G, Onida F, et al. Contribution of beta-2 microglobulin levels to the prognostic stratification of survival in patients with myelodysplastic syndrome (MDS). Blood. 2003; 102(5): 1622-5.

16. Neumann F, Gattermann N, Barthelmes HU, et al. Levels of beta 2 microglobulin have a prognostic relevance for patients with myelodysplastic syndrome with regard to survival and the risk of transformation into acute myelogenous leukemia. Leuk Res. 2009; 33(2): 232-6.

17. Nösslinger T, Tüchler H, Germing $U$, et al. Prognostic impact of age and gender in 897 untreated patients with primary myelodysplastic syndromes. Ann Oncol. 2010; 21(1): 120-5

18. Arber DA, Orazi A, Hasserjian R, et al. The 2016 revision to the World Health Organization classification of myeloid neoplasms and acute leukemia. Blood. 2016; 127(20): 2391-405

19. [Internet] National Cancer Institute. Surveillance, Epidemiology, and End Results Program. Accessed on 8 February 2018. Available online: https://seer.cancer.gov/.

20. Ansa BE, Coughlin SS, Alema-Mensah E, et al. Evaluation of Colorectal Cancer Incidence Trends in the United States (2000-2014). J Clin Med. 2018; 7(2): E22.

21. Vardiman JW, Thiele J, Arber DA, et al. The 2008 revision of the World Health Organization (WHO) classification of myeloid neoplasms and acute leukemia: rationale and important changes. Blood. 2009; 114(5): 937-51.

22. Ganguly BB, Kadam NN. Mutations of myelodysplastic syndromes (MDS): An update. Mutat Res Rev Mutat Res. 2016; 769: 47-62.

23. World Health Organization. International Classification of Diseases for Oncology (ICD-O), Third edition, First revision. 2013; 12.

24. Wang $\mathrm{R}$, Gross $\mathrm{CP}$, Halene $\mathrm{S}$, et al. Comorbidities and survival in a large cohort of patients with newly diagnosed myelodysplastic syndromes. Leuk Res. 2009; 33(12): 1594-8.

25. Ma X. Epidemiology of myelodysplastic syndromes. Am J Med. 2012; 125(7 Suppl): S2-5.

26. Vardiman JW, Harris NL, Brunning RD. The World Helth Organization (WHO) classification of the myeloid neoplasms. Blood. 2002; 100(7): 2292-302.

27. Jung $\mathrm{SH}, \mathrm{Kim} \mathrm{YJ}$, Yim SH, et al. Somatic mutations predict outcomes of hypomethylating therapy in patients with myelodysplastic syndrome. Oncotarget. 2016; 7(34): 55264-75.

28. Kawabata $\mathrm{H}$, Tohyama $\mathrm{K}$, Matsuda $\mathrm{A}$, et al. Validation of the revised International Prognostic Scoring System in patients with myelodysplastic syndrome in Japan: results from a prospective multicenter registry. Int J Hematol. 2017; 106(3): 375-84.

29. Moreno Berggren D, Folkvaljon Y, Engvall M, et al. Prognostic scoring systems for myelodysplastic syndromes (MDS) in a population-based setting: a report from the Swedish MDS register. Br J Haematol. 2018; 181(5): 614-27.

30. Malcovati L, Porta MG, Pascutto C, et al. Prognostic factors and life expectancy in myelodysplastic syndromes classified according to WHO criteria: a basis for clinical decision making. J Clin Oncol. 2005; 23(30): 7549-603.

31. Sanz GF, Sanz MA, Vallespí T, et al. Two regression models and a scoring system for predicting survival and planning treatment in myelodysplastic syndromes: a multivariate analysis of prognostic factors in 370 patients. Blood. 1989; 74(1): 395-408.

32. Bammer C, Sperr WR, Kemmler G, et al. Clustering of comorbidities is related to age and sex and impacts clinical outcome in myelodysplastic syndromes. J Geriatr Oncol. 2014; 5(3): 299-306.

33. Zipperer E, Tanha N, Strupp $\mathrm{C}$, et al. The myelodysplastic syndrome-comorbidity index provides additional prognostic information on patients stratified according to the revised international prognostic scoring system. Haematologica. 2014; 99(3): e31-2.

34. Balleari E, Salvetti C, Del Corso L, et al. Age and comorbidities deeply impact on clinical outcome of patients with myelodysplastic syndromes. Leuk Res. 2015; 39(8): 846-52 
35. Nagvi K, Garcia-Manero G, Sardesai S, et al. Association of comorbidities with overall survival in myelodysplastic syndrome: development of a prognostic model. J Clin Oncol. 2011; 29(16): 2240-6.

36. Hannum G, Guinney J, Zhao L, et al. Genome-wide methylation profiles reveal quantitative views of human aging rates. Mol Cell. 2013; 49(2): 359-67.

37. Jemielity S, Kimura M, Parker KM, et al. Short telomeres in short-lived males: what are the molecular and evolutionary causes? Aging Cell. 2007; 6(2): 225-33.

38. Cherif $\mathrm{H}$, Tarry JL, Ozanne SE, et al. Ageing and telomeres: a study into organand gender-specific telomere shortening. Nucleic Acids Res. 2003; 31(5): 1576-83.

39. Barrett EL, Richardson DS. Sex differences in telomeres and lifespan. Aging Cell. 2011; 10(6): 913-21.

40. DeZern AE, Zeidan AM, Barnard J, et al. Differential response to hypomethylating agents based on sex: a report on behalf of the MDS Clinical Research Consortium (MDS CRC). Leuk Lymphoma. 2017; 58(6): 1325-31.

41. Mahfouz RZ, Jankowska A, Ebrahem Q, et al. Increased CDA expression/activity in males contributes to decreased cytidine analog half-life and likely contributes to worse outcomes with 5-azacytidine or decitabine therapy. Clin Cancer Res. 2013; 19(4): 938-48. 